\title{
Relations of biomarkers of manganese exposure and neuropsychological effects among welders and ferroalloy smelters
}

\author{
Hamid HASSANI ${ }^{1,2}$, Farideh GOLBABAEI ${ }^{1 *}$, Hamid SHIRKHANLOO ${ }^{2,3}$ and \\ Mehdi TEHRANI-DOUST ${ }^{4}$
}

\footnotetext{
${ }^{1}$ Department of Occupational Health Engineering, School of Public Health, Tehran University of Medical Sciences, Iran

${ }^{2}$ Iranian Petroleum Industry Occupational and Environmental Health Research Center (IPIOEHRC), Iranian Petroleum Industry Health Research Institute (IPIHRI), Iran

${ }^{3}$ Research Institute of Petroleum Industry (RIPI), Iran

${ }^{4}$ Department of Psychiatry, School of Medicine, Tehran University of Medical Sciences, Iran
}

Received December 4, 2014 and accepted August 24, 2015

Published online in J-STAGE September 30, 2015

\begin{abstract}
The objective of present study was to assess relationship between biomarkers of Manganese (Mn) and neuropsychological effects. The study was carried out on 27 welders and 31 ferroalloy smelters as Mn-exposed groups and 30 office workers as unexposed controls. Air Mn concentrations were determined according to NIOSH method 7300. The biological samples were prepared using microwave assisted acid digestion and all samples were analyzed by graphite furnace- atomic absorption spectroscopy (GF-AAS) in order to determine manganese. Questionnaire 16 (Q16) and Cambridge Neuropsychological Test Automated Battery (CANTAB) were used to evaluate the neuropsychological effects. The mean concentrations of air Mn for the welder and ferroalloy smelter groups were $0.023 \pm 0.012 \mathrm{mg} / \mathrm{m}^{3}$ and $0.008 \pm 0.005 \mathrm{mg} / \mathrm{m}^{3}$, respectively. Manganese concentrations in blood, urine, and toenail samples of exposed workers ranged between $1.80-32.60(\mu \mathrm{g} / \mathrm{l})$, $1.00-42.50(\mu \mathrm{g} / \mathrm{l})$, and $0.10-6.08(\mu \mathrm{g} / \mathrm{g})$, respectively. Mean Mn concentrations in all biological samples of cases were significantly higher than unexposed controls $(p<0.05)$. A moderate relationship was observed between biomarkers of Mn exposure, air Mn, Q16 as well as some neurocognitive outcome measures. The present study shows that blood Mn, urine Mn and toenail Mn could be used to distinguish Mn-exposed workers from unexposed population at the group level.
\end{abstract}

Key words: Biomarkers of manganese exposure, Blood, Neuropsychological effects, Toenail, Urine, Welding and smelting processes

\section{Introduction}

Manganese (Mn) is an essential element for many

*To whom correspondence should be addressed.

E-mail: fgolbabaei@sina.tums.ac.ir

(C)2016 National Institute of Occupational Safety and Health biological functions in human being ${ }^{1-3)}$. However, overexposure to Mn can cause health problems especially neurotoxicity ${ }^{4}$. Manganese accumulates in brain regions and it can cause central nervous system (CNS) abnormalities as well as neuropsychiatric disorders ${ }^{5)}$. The respiratory system is the most important way of Mn absorption for workers in the Mn-related industries. In this matter, entry 
of $\mathrm{Mn}$ to brain via the olfactory nerve has been reported as the main pathway6).

Occupational exposure to $\mathrm{Mn}$ occurs in various industrial processes such as welding, ferroalloy steel production and dry cell battery manufacturing ${ }^{7,8}$. A significant number of studies have shown that welders are exposed to high concentrations of Mn-containing welding fumes which leads to increasing the prevalence of neurobehavioral symptoms among them ${ }^{3,5,7,9-14)}$. Several neurobehavioral symptoms have also been reported among the ferroalloy smelting workers exposed to $\mathrm{Mn}^{15-17)}$. Ellingsen et al., in a study on welders, reported that $\mathrm{Mn}$ exposures ranged between 0.003 to $4.26 \mathrm{mg} / \mathrm{m}^{3,18)}$. Two neurological function alterations including Impaired Finger Tapping Speed and Grooved Pegboard Performance were considerable among former welders ${ }^{13)}$. Wastensson et al., in a study on ship welders, showed that long-term exposure to $\mathrm{Mn}$ can have adverse effect on motor function ${ }^{3)}$. Occupational exposure to Mn can also affect other systems including respiratory, cardiac, liver and reproductive systems ${ }^{6,7)}$. A study on smelting workers by Cowan et al. ${ }^{8)}$ showed that airborne Mn concentration ranged between 0.01 to $0.374 \mathrm{mg} / \mathrm{m}^{3}$. Cowan et al. ${ }^{17)}$ have found a relationship between blood manganese-iron ratio and early onset neurobehavioral alterations. Bouchard et al. ${ }^{16)}$ have shown an exposureeffect relation for symptoms related to memory, concentration and balance in a group of Mn-alloy workers.

Biological monitoring (or biomonitoring) is a useful tool for occupational exposure assessment and potential related health risks ${ }^{19)}$. Biomonitoring provides valuable information that can be used to prevent adverse health effects. Having studied potential biomarkers of Mn including Mn in blood, urine and hair, Bader et al. ${ }^{20)}$ reported that blood $\mathrm{Mn}$ is better than urine and/or hair Mn for assessment of $\mathrm{Mn}$ exposure. In their study, the mean concentration of blood Mn was $12.2 \pm 4.8 \mu \mathrm{g} / 1$ (ranged: $3.2-25.8 \mu \mathrm{g} / \mathrm{l}$ ). Similarly, Wongwit et al. ${ }^{21)}$ suggested the blood Mn as a recommended biomarker in occupational studies. However, Crossgrove and Zheng ${ }^{6}$ noted that blood Mn indicates recent exposure, thus, it can't be used to assess longterm effects. The number of studies on biomarkers of $\mathrm{Mn}$ exposure has been increased during recent two decades, but suitable biomarkers are not well determined.

The objectives of this study were: 1) to assess the correlation between air $\mathrm{Mn}$, blood $\mathrm{Mn}$, urine $\mathrm{Mn}$, and toenail Mn concentrations, 2) to evaluate the neurobehavioral symptoms, and 3) to examine the relations of biomarkers of $\mathrm{Mn}$ exposure with neurobehavioral and neurocognitive outcome measures among welders and ferroalloy smelters as two occupationally Mn-exposed groups.

\section{Subjects and Methods}

\section{Subjects}

This cross-sectional study was carried out in an automotive parts manufacturing industry in Tehran, Iran, in 2013. Workers who had more than $1 \mathrm{yr}$ of work history were recruited for the study. The exclusion criteria were similar to previous studies ${ }^{12,13,15)}$, including: alcohol consumption, drug abuse, diabetes mellitus, damages of central nerves system (CNS) such as concussion, prior exposure to organic solvents and neurotoxic metals (e.g., lead and mercury), and serious kidney or liver diseases. Based on $95 \%$ confidence intervals and $80 \%$ power of statistical test, the number of calculated sample (sample size) was at least 27 for each group. Therefore, decision was made to recruit about 30 workers for each study group. 30 welders, 31 ferroalloy smelters and 30 office workers were invited to participate in the study. One welder refused and 2 others were excluded from this study due to kidney disease records. After exclusions, 27 welders and 31 ferroalloy smelters as exposed groups (cases) and 30 office workers as unexposed control group were involved in the study (participation rate: $96.70 \%$ ). It should be noted that the unexposed controls were selected from matched people of the same sex (male), age, work history, and education level without any diseases affecting. In this study, the accuracy of participants' answers relating to alcohol consumption and drug abuse was based on two factors: firstly, all participants were volunteers who were informed about objectives of study, importance of their answers, and ethical issues. Informed consents were obtained from participants. The study was approved by ethics committee at Tehran University of Medical Sciences (TUMS). Secondly, there were no medical history of related items in medical records of the studied participants.

In the studied industry, workers were working $44 \mathrm{~h}$ per wk. The average time of welding was about $4 \mathrm{~h}$ per $\mathrm{d}$ during a work shift.

Most exposed workers (77.59\%) reported that they usually uses respiratory protection masks (Type: FFP3/ EN149:2001 series).

\section{Work description}

Welding type

The type of welding was Shielded Metal Arc Welding (SMAW) and two types of electrode were used (E 6013 and $\mathrm{E}$ 7018). The percentage of $\mathrm{Mn}$ in these electrodes 
was about 0.50 to 0.90 . Welders were exposed to $\mathrm{Mn}$ containing welding fumes through inhalation during welding processes. Welding fumes contains metals especially iron, manganese $(\mathrm{Mn})$, chromium, and nickel ${ }^{7)}$. Among these metals, $\mathrm{Mn}$ is a well-known neurotoxic metal.

\section{Smelting process}

Eight furnaces were operated for smelting process in the studied industry (producing grey iron and ductile iron automotive parts). The percentage of $\mathrm{Mn}$ in the molten materials was about 0.30 to 0.50 .

Iron, manganese $(\mathrm{Mn})$, nickel, graphite, and silicon were commonly used in the studied industry. Like welding fumes, smelting fumes also contains $\mathrm{Mn}$. So, Smelters were exposed to Mn-containing smelting fumes through inhalation during smelting processes.

\section{Collection of air samples and analysis}

Personal air samples were collected using mixed cellulose ester membrane filters $(0.8 \mathrm{~mm}$ pore size, $25 \mathrm{~mm}$ diameter; SKC Corp) and SKC pumps (224-PCMTX8, 224-PCMTX8, S/No. 09523488- SKC Ltd. DT11 8ST. UK). The flow rate of pumps was adjusted at $2.01 / \mathrm{min}$ for sampling. All pumps were calibrated before and after use and the mean of flow rate was considered in calculations. Analysis was done using graphite furnace-atomic absorption spectroscopy (GF-AAS) according to NIOSH analytical method $7300^{22)}$.

\section{Biological monitoring}

Biological samples including blood, urine and toenail samples were collected at the end of work shift. The time lag between collecting air samples and biological samples was about $7 \mathrm{~d}$. It should be noted that all of the biological samples were collected at the same working day.

Five milliliter ( $\mathrm{ml}$ ) of venous blood was collected from each worker. Blood samples were divided into two tubes ( $4 \mathrm{ml}$ in a heparinized tube and $1 \mathrm{ml}$ in a non- heparinized tube). Urine samples were collected in polyethelene tubes and for each sample $1 \mathrm{ml}$ nitric acid was added per $10 \mathrm{ml}$ urine sample. Toenails were from all toes of participants. Superficial contamination was removed by sonicating toenail samples in $10 \mathrm{ml} 1 \%$ Tritone $\mathrm{X}-100$ solution for 20 min and then washed with deionized water and they were dried before weighting.

\section{Digestion method for biological samples}

The biological samples were prepared using microwave assisted acid digestion (Microwave digestion- EPA
Method 3052 on the Multiwave 3000). In this clean and reproducible closed digestion method, the quality assurance/quality control (QA/QC) has been improved. Another benefit of microwave assisted acid digestion method is reduced preparation time ${ }^{23)}$. Nitric acid, hydrochloric acid, and hydrogen peroxide were used as reagents. After adding reagents in the reaction vessels with the biological samples, vessels were placed in the microwave.

\section{Analysis of biological samples}

The graphite furnace-atomic absorption spectroscopy (GF-AAS) was used for analysis of biological samples. The validity of analytical method was examined by using Standard Reference Material (SRM 2670a, NIST). Data showed that the recovery percentage was $96.2 \%$ (SRM: $2.6 \pm 0.7 \mu \mathrm{g} / \mathrm{l}$, value obtained: $2.5 \pm 0.4 \mu \mathrm{g} / \mathrm{l})$. The Limit of Qountitation (LOQ), Limit of Detection (LOD) and linear range for Mn analysis were $1.0 \mu \mathrm{g} / 1,0.25 \mu \mathrm{g} / \mathrm{l}$, and $1-35 \mu \mathrm{g} / 1$, respectively.

\section{Neurobehavioral symptoms}

In this study, the questionnaire $16(\mathrm{Q} 16)^{24)}$ was used for assessing neurobehavioral symptoms. This questionnaire contains 16 Yes/No questions about abnormal tiredly, painful tingling in body, palpitation, irritation and depression without particular reason, problem with concentrating, having a short memory, perspire without particular reason, problems with buttoning and unbuttoning, difficulties to get the meaning from reading newspapers or books, oppression of chest, memory problems, headache (at least once a week), and being less interested in sex. The frequency of neurobehavioral symptoms of welders and ferroalloy smelters was compared to unexposed office workers.

\section{Neurocognitive tests}

Neurocognitive tests including choice reaction time (CRT) as an attention test, spatial working memory (SWM) as an executive function test, paired associates learning (PAL) as a visual memory test, and stocking of Cambridge (SOC) as a planning test were performed using Cambridge Neuropsychological Test Automated Battery $(\text { CANTAB })^{25)}$. This computerized cognitive assessment tool would improve the quality of study data, providing greater sensitivity with maximization of standardization of administration and scoring as well as the precision of measurement compared to manually-administered (paper and pencil) test batteries used in previous studies. 
Table 1. The demographic Information of the study groups

\begin{tabular}{lcccccc}
\hline \multicolumn{1}{c}{ Groups } & $\mathrm{n}$ & $\begin{array}{c}\text { Age }(\mathrm{yr}) \\
(\text { Mean } \pm \mathrm{SD})\end{array}$ & $\begin{array}{c}\text { Work history }(\mathrm{yr}) \\
(\text { Mean } \pm \mathrm{SD})\end{array}$ & $\begin{array}{c}\mathrm{BMI}\left(\mathrm{kg} / \mathrm{m}^{2}\right) \\
(\text { Mean } \pm \mathrm{SD})\end{array}$ & $\begin{array}{c}\text { Number of smokers } \\
(\%)\end{array}$ & $\begin{array}{c}\text { Number of married } \\
\text { people }(\%)\end{array}$ \\
\hline Welder & 27 & $31.18 \pm 4.06$ & $7.04 \pm 4.64$ & $24.47 \pm 2.92$ & $7(25.92)$ & $24(88.88)$ \\
Control & 30 & $34.45 \pm 7.11$ & $8.61 \pm 4.70$ & $26.11 \pm 4.72$ & $4(13.33)$ & $26(86.66)$ \\
$p$ value & - & 0.053 & 0.228 & 0.149 & 0.248 & 0.597 \\
Ferroalloy smelter & 31 & $34.88 \pm 5.63$ & $9.15 \pm 4.38$ & $27.06 \pm 4.15$ & $7(22.58)$ & $28(90.32)$ \\
Control & 30 & $34.45 \pm 7.11$ & $8.61 \pm 4.70$ & $26.11 \pm 4.72$ & $4(13.33)$ & $26(86.66)$ \\
$p$ value & - & 0.789 & 0.638 & 0.404 & 0.384 & 0.155 \\
\hline
\end{tabular}

*Differences between case and control groups, Student's $t$-test, $p<0.05$; statistically significant

Table 2. Mn concentrations in air, blood, urine, and toenail samples

\begin{tabular}{llcccc}
\hline \multicolumn{1}{c}{ Groups } & Sample $(\mathrm{unit})$ & $\mathrm{n}$ & Mean $\pm \mathrm{SD}$ & Range & $p$ value \\
\hline Welder & Air $\left(\mathrm{mg} / \mathrm{m}^{3}\right)$ & 27 & $0.023 \pm 0.012$ & $0.002-0.062$ & - \\
& Blood $(\mu \mathrm{g} / \mathrm{l})$ & 27 & $15.85 \pm 7.11$ & $1.80-32.60$ & $\mathbf{0 . 0 0 7}$ \\
& Urine $(\mu \mathrm{g} / \mathrm{l})$ & 27 & $13.00 \pm 7.98$ & $1.00-24.10$ & $\mathbf{0 . 0 2 6}$ \\
& Toenail $(\mu \mathrm{g} / \mathrm{g})$ & 24 & $3.08 \pm 1.44$ & $1.15-6.08$ & $<\mathbf{0 . 0 0 1}$ \\
Ferroalloy smelter & Air $\left(\mathrm{mg} / \mathrm{m}^{3}\right)$ & 31 & $0.008 \pm 0.005$ & $0.002-0.029$ & - \\
& Blood $(\mu \mathrm{g} / \mathrm{l})$ & 31 & $17.33 \pm 8.66$ & $4.00-32.06$ & $\mathbf{0 . 0 0 1}$ \\
& Urine $(\mu \mathrm{g} / \mathrm{l})$ & 31 & $12.56 \pm 10.00$ & $1.00-42.50$ & $\mathbf{0 . 0 4 7}$ \\
& Toenail $(\mu \mathrm{g} / \mathrm{g})$ & 31 & $1.52 \pm 0.95$ & $0.10-3.70$ & $\mathbf{0 . 0 4 8}$ \\
Case (Welder and & Air $\left(\mathrm{mg} / \mathrm{m}^{3}\right)$ & 58 & $0.014 \pm 0.011$ & $0.002-0.062$ & - \\
& Blood $(\mu \mathrm{g} / \mathrm{l})$ & 58 & $16.74 \pm 8.04$ & $1.80-32.60$ & $<\mathbf{0 . 0 0 1}$ \\
& Urine $(\mu \mathrm{g} / \mathrm{l})$ & 58 & $12.73 \pm 9.17$ & $1.00-42.50$ & $\mathbf{0 . 0 1 8}$ \\
& Toenail $(\mu \mathrm{g} / \mathrm{g})$ & 55 & $2.14 \pm 1.39$ & $0.10-6.08$ & $\mathbf{0 . 0 0 1}$ \\
& Blood $(\mu \mathrm{g} / \mathrm{l})$ & 30 & $9.37 \pm 8.70$ & $1.00-33.40$ & - \\
& Urine $(\mu \mathrm{g} / \mathrm{l})$ & 30 & $7.86 \pm 7.82$ & $1.00-27.80$ & - \\
& Toenail $(\mu \mathrm{g} / \mathrm{g})$ & 28 & $1.08 \pm 1.02$ & $0.10-4.47$ & - \\
\hline
\end{tabular}

*Comparison with control, Student's $t$-test, $p<0.05$; statistically significant

\section{Statistical analyses}

Data were analyzed using descriptive statistics, compare means, Mann-Whitney test, and partial correlation tests. Student's $t$-test was used to determine differences among means for some characteristics as well as Mn concentrations in air, blood, urine, and toenail samples of case and control groups. Comparisons between medians of Q16 (Number of positive answers) of studied groups were performed using Mann-Whitney test. Partial correlation tests were carried out to determine the correlation among air, blood, urine and toenail samples, neurobehavioral symptoms (Q16 score) as well as neurocognitive outcome measures in the exposed groups. We used the statistical package for the social sciences software (SPSS version 17) for all statistical analyses. Results were considered statistically significant at $p<0.05$.

\section{Results}

The demographic information of the case and control groups is shown in Table 1. There were no significant differences between the case and control groups in terms of age, work history, body mass index (BMI), smoking, and marriage status.

The Mn concentrations in air, blood, urine, and toenail samples of our study population are shown in Table 2 . The mean concentrations of air $\mathrm{Mn}$ for the welder and ferroalloy smelter groups were $0.023 \pm 0.012 \mathrm{mg} / \mathrm{m}^{3}$ (range: $0.002-0.062 \mathrm{mg} / \mathrm{m}^{3}$ ) and $0.008 \pm 0.005 \mathrm{mg} / \mathrm{m}^{3}$ (range: $0.002-0.029 \mathrm{mg} / \mathrm{m}^{3}$ ), respectively.

Manganese concentrations in blood, urine, and toenail samples of exposed workers ranged between $1.80-32.60(\mu \mathrm{g} / \mathrm{l}), 1.00-42.50(\mu \mathrm{g} / \mathrm{l})$, and $0.10-6.08(\mu \mathrm{g} /$ $\mathrm{g}$ ), respectively. As it is shown in Table 2, the mean $\mathrm{Mn}$ concentrations in all biological samples were significantly 
higher in the welders and ferroalloy smelters than in the unexposed controls $(p<0.05)$.

The number of self-reported neurobehavioral symptoms was significantly more prevalent among welders and ferroalloy smelters than among unexposed controls $(p<0.001)$, (Table 3).

The results of partial correlation showed that there were significant relationships between blood $\mathrm{Mn}$ and toenail Mn with Q16 score, and urine Mn with toenail Mn in the welder group. Correlations between blood Mn with urine $\mathrm{Mn}$, toenail $\mathrm{Mn}$, and air $\mathrm{Mn}$, as well as urine Mn with toenail Mn and air Mn were statistically significant in the ferroalloy smelter group (Table 4).

Table 5 shows significant inverse relationships between neurocognitive outcome measures and biomarkers of $\mathrm{Mn}$ exposure. The correlation coefficients ranged from 0.299 to $0.566,(p<0.05)$.

\section{Discussion}

The results of this study showed that the concentrations of $\mathrm{Mn}$ in biological samples (blood, urine, and toenail) of both welder and ferroalloy smelter groups were significantly higher than the unexposed-control group. Welders and ferroalloy smelters reported more neurobehavioral symptoms than the controls. Significant relationships were also observed between blood $\mathrm{Mn}$ and toenail $\mathrm{Mn}$ with the number of neurobehavioral symptoms in the welder group. We found significant inverse relationships between some neurocognitive outcome measures and biomarkers of $\mathrm{Mn}$ exposure.

The results of previous studies on biomarkers of $\mathrm{Mn}$ exposure are contradictory, thus sufficient data, well quantitative and qualitative studies, and review of literature are needed to determine reliable biological indicators. Some previous studies showed that the blood $\mathrm{Mn}$ and urine $\mathrm{Mn}$ levels of exposed workers were significantly higher than unexposed controls ${ }^{2,4,21,26)}$. Consistently, our results showed that blood Mn and urine Mn can be utilized for distinguishing exposed from unexposed workers at the group based level. Bader et al. ${ }^{20)}$ examined the relationship between the Mn dioxide $\left(\mathrm{MnO}_{2}\right)$ exposure and three potential biomarkers including blood, urine and axillary hair in a study on dry cell battery manufacturers. They concluded that blood $\mathrm{Mn}$ is better indicator than urine and hair $\mathrm{Mn}$ for the biomonitoring of $\mathrm{MnO}_{2}$ exposure. Similarly, blood $\mathrm{Mn}$ is recommended by Wongwit et al. ${ }^{21)}$ for the biomonitoring of Mn exposure among occupationallyexposed workers. In Laohaudomchok et al. ${ }^{27)}$ study,
Table 3. Neurobehavioral symptoms in the exposed and unexposed workers

\begin{tabular}{lcccc}
\hline \multirow{2}{*}{ Groups } & $\mathrm{n}$ & \multicolumn{2}{c}{ Q16, No of positive answers } & \\
\cline { 3 - 4 } & & Median & Range & \\
\hline Welder & 27 & 3 & $1-10$ & $<\mathbf{0 0 / 0 0 1}$ \\
Ferroalloy smelter & 31 & 4 & $1-11$ & $<\mathbf{0 / 0 0 1}$ \\
Control & 30 & 1 & $0-6$ & - \\
\hline
\end{tabular}

*Comparison with control, Mann-Whitney test, $p<0.05$; statistically significant

toenail Mn was significantly correlated with cumulative $\mathrm{Mn}$ exposure indices; however, there were no significant correlation between blood $\mathrm{Mn}$ and urine $\mathrm{Mn}$ with cumulative $\mathrm{Mn}$ exposure indices. According to this finding, toenail Mn could be used as a suitable biomarker for longterm exposure assessment. This shows that the toenail Mn might be considered as a biomarker of exposure and effect. Similar to Laohaudomchok et al. ${ }^{27)}$ study, our results showed that toenail $\mathrm{Mn}$ seems to be a useful biomarker of exposure and effect. In general, blood $\mathrm{Mn}$ and urine $\mathrm{Mn}$ could be used as two practical biomarkers in the group based studies. However, toenail $\mathrm{Mn}$ is the preferred biomarker for long-term exposure assessment.

Despite the difference in air Mn levels between the two exposed groups, the blood $\mathrm{Mn}$ and urine Mn levels were similar among the welders and ferroalloy smelters. One reason of this observation was that the individual air $\mathrm{Mn}$ measurement for just one day may not represent actual individual exposure. Also, it is worth noting that half-life of Mn varies in blood, urine, and toenail (hours or several days in blood and urine, and several months in toenail). So, we suggest to consider the cumulative exposure index (CEI) for future studies.

Although mean air Mn concentrations for both of our studied groups were below the Occupational Exposure Limit -Time Weighted Average (OEL-TWA; $0.2 \mathrm{mg} / \mathrm{m}^{3}$ ) recommended by Environmental and Occupational Health Center of the Ministry of Health and Medical Education of $\operatorname{Iran}^{28)}$, the number of self-reported neurobehavioral symptoms was significantly higher in the Mn-exposed workers. Thus, there is a need to modify the current OEL-TWA for $\mathrm{Mn}$ to prevent the occurrence of related adverse effects especially neurotoxicity. In other words, a revised OELTWA for Mn (lower than $0.2 \mathrm{mg} / \mathrm{m}^{3}$ ) can protect nearly all industrial workers.

"The questionnaire 16 (Q16) is commonly used to study prevalence of neurotoxic symptoms among workers exposed to organic solvents."24). However, a few studies 
Table 4. Partial correlation *of Mn concentrations among air, blood, urine, and toenail samples and associations with neurobehavioral symptoms (Q16 score) in the exposed groups

\begin{tabular}{|c|c|c|c|c|c|c|c|c|c|}
\hline \multirow{2}{*}{ Groups } & \multirow{2}{*}{ Variable } & \multicolumn{2}{|c|}{ Blood } & \multicolumn{2}{|c|}{ Urine } & \multicolumn{2}{|c|}{ Toenail } & \multicolumn{2}{|c|}{ Air } \\
\hline & & $\mathrm{r}$ & $p$ value & $\mathrm{r}$ & $p$ value & $\mathrm{r}$ & $p$ value & $\mathrm{r}$ & $p$ value \\
\hline \multirow[t]{4}{*}{ Welder } & Urine & 0.507 & 0.016 & - & - & - & - & - & - \\
\hline & Toenail & 0.209 & 0.376 & 0.541 & 0.014 & - & - & - & - \\
\hline & Air & 0.332 & 0.131 & 0.218 & 0.329 & 0.397 & 0.083 & - & - \\
\hline & Q16 & 0.437 & 0.042 & 0.335 & 0.128 & 0.646 & 0.002 & 0.224 & 0.304 \\
\hline \multirow[t]{4}{*}{ Ferroalloy smelter } & Urine & 0.679 & $<0.001$ & - & - & - & - & - & - \\
\hline & Toenail & 0.646 & $<0.001$ & 0.649 & $<0.001$ & - & - & - & - \\
\hline & Air & 0.377 & 0.030 & 0.407 & 0.019 & 0.304 & 0.097 & - & - \\
\hline & Q16 & 0.087 & 0.643 & 0.046 & 0.801 & 0.200 & 0.280 & 0.302 & 0.083 \\
\hline
\end{tabular}

*Adjusted for age, work history and smoking. $p<0.05$; statistically significant

Table 5. Significant correlations * between neurocognitive outcome measures and biomarkers of manganese exposure in the exposed groups

\begin{tabular}{llcc}
\hline \multicolumn{1}{c}{ Groups } & \multicolumn{1}{c}{ Variables } & $\mathrm{r}$ & $p$ value \\
\hline Welder & PAL Stages completed on first trial \& Mn- Urine & -0.546 & $\mathbf{0 . 0 1 9}$ \\
& PAL Total error 6 shape \& Mn- Toenail & -0.470 & $\mathbf{0 . 0 4 9}$ \\
\hline Ferroalloy smelter & SWM Double error \& Mn- Blood & -0.426 & $\mathbf{0 . 0 3 8}$ \\
& SWM Double error \& Mn- Urine & -0.566 & $\mathbf{0 . 0 0 4}$ \\
& SWM Double error \& Mn- Toenail & -0.503 & $\mathbf{0 . 0 1 2}$ \\
& SWM Double error (8 boxes) \& Mn- Urine & -0.422 & $\mathbf{0 . 0 4 0}$ \\
& SWM Whthin errors \& Mn- Blood & -0.425 & $\mathbf{0 . 0 3 8}$ \\
Ferroalloy smelter) & SOC Mean subsequent thinking time (4 moves) \& Mn- Blood & -0.512 & $\mathbf{0 . 0 1 0}$ \\
\hline & SOC Mean subsequent thinking time (4 moves) \& Mn- Urine & -0.299 & $\mathbf{0 . 0 4 8}$ \\
& SWM Double error \& Mn- Blood & -0.407 & $\mathbf{0 . 0 0 6}$ \\
& SWM Double error \& Mn- Urine & -0.376 & $\mathbf{0 . 0 1 2}$ \\
& SWM Double error (8 boxes) \& Mn- Blood & -0.300 & $\mathbf{0 . 0 4 8}$ \\
& SWM Double error (8 boxes) \& Mn- Urine & -0.318 & $\mathbf{0 . 0 3 5}$ \\
& SWM Whthin errors \& Mn- Blood & -0.445 & $\mathbf{0 . 0 0 2}$ \\
& SWM Whthin errors \& Mn- Urine & -0.435 & $\mathbf{0 . 0 0 3}$ \\
& SWM Whitin error (6 boxes) \& Mn- Blood & -0.299 & $\mathbf{0 . 0 4 9}$ \\
\hline
\end{tabular}

*Adjusted for age, work history and smoking. $p<0.05$; statistically significant

used the Q16 for investigating neurobehavioral symptoms among welders $\left.{ }^{13}, 29,30\right)$. In a study on welders by Ellingsen et al. ${ }^{13)}$, the arithmetic mean of Q16 positive answers was 3.6 (range: 1-13). In our study, the median of positive answers for the welder and ferroalloy smelter groups were 3 (range: 1-10) and 4 (range: 1-11), respectively. Generally, Mn-exposed groups reported more neurobehavioral symptoms than unexposed controls.

The correlation test showed statistically significant associations between biomarkers of $\mathrm{Mn}$ exposure, air $\mathrm{Mn}$ and Q16. Correlation coefficients ranged between $0.377-0.679$ (moderate relationship) for observed significant associa- tions. As a result, a direct relationship between the level of Mn exposure and the number of neurotoxic symptoms was found.

Laohaudomchok et al. ${ }^{31)}$ suggested that even a lowlevel Mn exposure may have neuropsychological effects on welders. In their study, welders' cumulative Mn exposure index (Mn-CEI) was significantly associated with slower reaction time as well as worse mood. Similarly, Wastensson et al. ${ }^{3)}$ showed that the poorer performance in the grooved pegboard test, as a neuromotor function test, was associated with Mn-CEI among welders. Using the computerized cognitive assessment tool "CANTAB" 
for neurocognitive tests in the current study, the accuracy and precision of our neurocognitive results seems to be more reliable compared to those previous studies that have used manually-administered test batteries. Our results showed that biomarkers of Mn exposure were significantly correlated with some neurocognitive outcome measures. An increase in level of $\mathrm{Mn}$ in biological samples results in a decrease in neurocognitive performances (negative relationship). However, similar to many field studies, the major limitation of this cross-sectional study was small sample size. Therefore, we suggest a longitudinal study on large samples for further research. A potential limitation of this study is the lack of information related to dietary patterns among workers. In a similar study, Laohaudomchok et al. ${ }^{27)}$ have noted that "Mn from food intake may not make a significant contribution to internal dose". However, we collected and analyzed ten drinking water samples to control Mn levels in drinking water as a potential confounding factor. The results showed that the mean concentration of $\mathrm{Mn}$ in drinking water samples was 22.1 $\pm 0.9 \mu \mathrm{g} / 1$ which was lower than acceptable concentration for $\mathrm{Mn}$ in drinking water $(50 \mu \mathrm{g} / \mathrm{l})$. Therefore, it couldn't have significant effect on the obtained results. Another potential limitation of the present study seems to be the lack of data related to ventilation system efficiency. In general, one advantage of this case-control study is comparing the different biomarkers of Mn exposure among two Mnexposed groups. Significant relations of biomarkers of Mn exposure with neuropsychological effects indicates adverse effects among welder and smelter groups.

The current Occupational Exposure Limit-Time Weighted Average of Mn (OEL-TWA; $0.2 \mathrm{mg} / \mathrm{m}^{3}$ ) seems not providing sufficient protection against the neuropsychological effects. So, a change is needed to modify the current OELTWA of Mn for protecting exposed workers. The present study showed that blood Mn, urine Mn and toenail Mn could be used to distinguish Mn-exposed workers from unexposed population at the group level. Further studies are needed to identify reliable biomarkers for assessing Mn exposure at the individual level as well as to determine suitable biomarkers and biological exposure indices (BEIs) for Mn with concerning neuropsychological effects.

\section{Acknowledgements}

We would like to thanks Mr. Majid Minaei, Mr. Ahmad Mirzaei, Ms. Azar Mohammadzadeh, Mrs. Somayeh Farhang Dehghan and Mrs. Sarvar Charehdar for their kind assistance during this research. This study was supported by Tehran University of Medical Sciences.

\section{References}

1) Zheng W, Fu SX, Dydak U, Cowan DM (2011) Biomarkers of manganese intoxication. Neurotoxicology 32, 1-8. [Medline] [CrossRef]

2) Järvisalo J, Olkinuora M, Kiilunen M, Kivistö H, Ristola P, Tossavainen A, Aitio A (1992) Urinary and blood manganese in occupationally nonexposed populations and in manual metal arc welders of mild steel. Int Arch Occup Environ Health 63, 495-501. [Medline] [CrossRef]

3) Wastensson G, Sallsten G, Bast-Pettersen R, Barregard L (2012) Neuromotor function in ship welders after cessation of manganese exposure. Int Arch Occup Environ Health 85, 703-13. [Medline] [CrossRef]

4) Ellingsen DG, Hetland SM, Thomassen Y (2003) Manganese air exposure assessment and biological monitoring in the manganese alloy production industry. $\mathrm{J}$ Environ Monit 5, 84-90. [Medline] [CrossRef]

5) Antonini JM, Santamaria AB, Jenkins NT, Albini E, Lucchini R (2006) Fate of manganese associated with the inhalation of welding fumes: potential neurological effects. Neurotoxicology 27, 304-10. [Medline] [CrossRef]

6) Crossgrove J, Zheng W (2004) Manganese toxicity upon overexposure. NMR Biomed 17, 544-53. [Medline] [CrossRef]

7) Hassani H, Golbabaei F, Ghahri A, Hosseini M, Shirkhanloo H, Dinari B, Eskandari D, Fallahi M (2012) Occupational exposure to manganese-containing welding fumes and pulmonary function indices among natural gas transmission pipeline welders. J Occup Health 54, 316-22. [Medline] [CrossRef]

8) Cowan DM, Fan Q, Zou Y, Shi X, Chen J, Aschner M, Rosenthal FS, Zheng W (2009) Manganese exposure among smelting workers: blood manganese-iron ratio as a novel tool for manganese exposure assessment. Biomarkers 14, 3-16. [Medline] [CrossRef]

9) Hobson A, Seixas N, Sterling D, Racette BA (2011) Estimation of particulate mass and manganese exposure levels among welders. Ann Occup Hyg 55, 113-25. [Medline] [CrossRef]

10) Laohaudomchok W, Cavallari JM, Fang SC, Lin X, Herrick RF, Christiani DC, Weisskopf MG (2010) Assessment of occupational exposure to manganese and other metals in welding fumes by portable X-ray fluorescence spectrometer. J Occup Environ Hyg 7, 456-65. [Medline] [CrossRef]

11) Richman JD, Livi KJ, Geyh AS (2011) A scanning transmission electron microscopy method for determining manganese composition in welding fume as a function of primary particle size. J Aerosol Sci 42, 408-18. [Medline] [CrossRef]

12) Wang $X$, Yang Y, Wang X, Xu S (2006) The effect of occupational exposure to metals on the nervous system 
function in welders. J Occup Health 48, 100-6. [Medline] [CrossRef]

13) Ellingsen DG, Konstantinov R, Bast-Pettersen R, Merkurjeva L, Chashchin M, Thomassen Y, Chashchin V (2008) A neurobehavioral study of current and former welders exposed to manganese. Neurotoxicology 29, 48-59. [Medline] [CrossRef]

14) Sriram K, Lin GX, Jefferson AM, Roberts JR, Chapman RS, Chen BT, Soukup JM, Ghio AJ, Antonini JM (2010) Dopaminergic neurotoxicity following pulmonary exposure to manganese-containing welding fumes. Arch Toxicol 84, 521-40. [Medline] [CrossRef]

15) Bouchard M, Mergler D, Baldwin M, Panisset M, Roels HA (2007) Neuropsychiatric symptoms and past manganese exposure in a ferro-alloy plant. Neurotoxicology 28, 290-7. [Medline] [CrossRef]

16) Bouchard M, Mergler D, Baldwin ME, Panisset M (2008) Manganese cumulative exposure and symptoms: a followup study of alloy workers. Neurotoxicology 29, 577-83. [Medline] [CrossRef]

17) Cowan DM, Zheng W, Zou Y, Shi X, Chen J, Rosenthal FS, Fan Q (2009) Manganese exposure among smelting workers: relationship between blood manganeseiron ratio and early onset neurobehavioral alterations. Neurotoxicology 30, 1214-22. [Medline] [CrossRef]

18) Flynn MR, Susi P (2009) Neurological risks associated with manganese exposure from welding operations - a literature review. Int J Hyg Environ Health 212, 459-69. [Medline] [CrossRef]

19) Ong CN (1999) Reference values and action levels of biological monitoring in occupational exposure. Toxicol Lett 108, 127-35. [Medline] [CrossRef]

20) Bader M, Dietz MC, Ihrig A, Triebig G (1999) Biomonitoring of manganese in blood, urine and axillary hair following low-dose exposure during the manufacture of dry cell batteries. Int Arch Occup Environ Health 72, 521-7. [Medline] [CrossRef]

21) Wongwit W, Kaewkungwal J, Chantachum Y, Visesmanee V (2004) Comparison of biological specimens for manganese determination among highly exposed welders. Southeast Asian J Trop Med Public Health 35, 764-9. [Medline]

22) National Institute for Occupational Safety and Health (NIOSH) (2003) Manual of analytical methods, method 7300, 4th Ed. NIOSH, Cincinnati.

23) Mangum SJ (2009) Microwave digestion- EPA Method 3052 on the Multiwave 3000. Field application report. PerkinElmer Inc., Waltham.

24) Lundberg I, Högberg M, Michélsen H, Nise G, Hogstedt C (1997) Evaluation of the Q16 questionnaire on neurotoxic symptoms and a review of its use. Occup Environ Med 54, 343-50. [Medline] [CrossRef]

25) Cambridge Neuropsychological Test Automated Battery (CANTAB): http://www.cambridgecognition.com/ clinicaltrials/cantabsolutions/tests.

26) Apostoli P, Lucchini R, Alessio L (2000) Are current biomarkers suitable for the assessment of manganese exposure in individual workers? Am J Ind Med 37, 283-90. [Medline] [CrossRef]

27) Laohaudomchok W, Lin X, Herrick RF, Fang SC, Cavallari JM, Christiani DC, Weisskopf MG (2011) Toenail, blood, and urine as biomarkers of manganese exposure. J Occup Environ Med 53, 506-10. [Medline] [CrossRef]

28) Environmental and Occupational Health Center Ministry of Health and Medical Education, Iran (2012) Occupational Exposure Limits (OEL), last revision.

29) Sjögren B, Gustavsson P, Hogstedt C (1990) Neuropsychiatric symptoms among welders exposed to neurotoxic metals. Br J Ind Med 47, 704-7. [Medline]

30) Zoni S, Albini E, Lucchini R (2007) Neuropsychological testing for the assessment of manganese neurotoxicity: a review and a proposal. Am J Ind Med 50, 812-30. [Medline] [CrossRef]

31) Laohaudomchok W, Lin X, Herrick RF, Fang SC, Cavallari JM, Shrairman R, Landau A, Christiani DC, Weisskopf MG (2011) Neuropsychological effects of low-level manganese exposure in welders. Neurotoxicology 32, 171-9. [Medline] [CrossRef] 